\title{
Job Satisfaction among Physiotherapy Professionals Working In Private Sectors of Bangladesh: A Cross-Sectional Study
}

\section{Bahauddin Bayzid ${ }^{1}$, Mohammad Kamrujjaman ${ }^{\star, \dagger, 2}$, Abu Mohammad Musa $^{3}$, Mohammad Mizanur Rahman ${ }^{4}$, Md. Rejwan Gani Mazumder ${ }^{5}$}

\author{
${ }^{1}$ Course Coordinator 83 Assistant Professor, Department of Physiotherapy, SAIC College of Medical Science and Technology, Dhaka, \\ Bangladesh \\ ${ }^{2}$ Assistant Professor, Department of Physiotherapy, State College of Health Sciences, Dhaka, Bangladesh \\ ${ }^{3}$ Physiotherapist, Dhaka University Medical Centre, Dhaka, Bangladesh \\ ${ }^{4}$ Lecturer (Guest), Department of Physiotherapy, Institute of Health Technology, Dhaka, Bangladesh \\ ${ }^{5}$ Lecturer of Physiotherapy, Department of Physiotherapy, SAIC College of Medical Science and Technology, Dhaka, Bangladesh
}

(DDOI: https://doi.org/10.15520/jcmro.v2i09.195

Accepted 10-09-2019; Received 14-08-2019; Publish Online 13-09-2019

Reviewed By: Dr.

kratika Daniel

Department:

'Reviewer/CMRO

\begin{abstract}
Background: Job satisfaction is an integral part of an individual's Professional life. It denotes to the worker's perception of their workplace settings, relationships amid fellows, salary as well as endorsement opportunities. The objective of the study was to determine job satisfaction among physiotherapy professionals working in the private sector.

Methodology: A cross-sectional study was conducted in Dhaka, Bangladesh. A total of 103 graduate and postgraduate completed physiotherapy professionals working in the private sectors included in this study. The investigators used a structured questionnaire to collect the data from June to November 2018. Satisfaction level was evaluated by 4 -point Likert scale grading and ranging from $1=$ Strongly dissatisfaction, $2=$ Dissatisfaction, $3=$ Satisfaction, and $4=$ Strongly satisfaction.

Results: Results indicated that more than half of the participants were satisfied with their job. Without a salary structure and promotion system, most of the participant's consent on satisfaction about the working environment, leave policy, the security of job place, comfortable with senior, colleague behavior, and cooperation of colleagues. In addition, females were more satisfied than male and young professionals were more satisfied than the senior. However, there was a highly significant relationship found between salary and job satisfaction ( $\mathrm{p}$ value 0.001 ).

Conclusion: It is concluded from the study that a moderate number of participants in the private sector expressed their job satisfaction. Job satisfaction was influenced by some factors. It is noted that attention on salary structure and review of job might help to increase the level of satisfaction.
\end{abstract}

Key words: Job Satisfaction-Private Sector-Physiotherapy Professionals-Likert scale

\section{INTRODUCTION:}

Job and career satisfaction is a fundamental part of an individual's professional life that affects job performance [1].

\footnotetext{
* Corresponding author.

$\dagger$ Email: kamrujjaman10@gmail.com
}

Job satisfaction (JS) refers to a person's feeling of satisfaction on the job which acts as a motivation to work [2]. JS is varied by cultural and gender differences [3]. The factors influencing JS is salary and wages, promotion changes, working conditions, company policies, Workgroup, paperwork, challenge, physical and stress [4]. Physiotherapy professionals are high risk for burnout and role conflict and their JS 


\section{Job Satisfaction among Physiotherapy Professionals Working In Private Sectors of Bangladesh: A Cross-Sectional Study

levels are significantly lower than other professions [5]. In Bangladesh, a physiotherapist is certified in physiotherapy practice after completing a five year university degree. Physiotherapy profession has 50 years of history in our country. Due to rapid population growth and increasing senior citizen, rehabilitation services now becoming an important issue in Bangladesh. Currently, rehabilitation services are provided by both public and private health sectors. Evaluation of job satisfaction will help to know the information on both the positive and negative aspects in daily working condition [4]. To get better satisfaction we have to evaluate and measure JS and also reward and recognition. Physiotherapist plays a vital role in both preventive and rehabilitative health care [6]. If the job satisfaction level and determinants are identified, necessary action can be taken to increase levels of satisfaction and consequently improve the quality of rehabilitation services on offer to the public [6]. Evaluation of job satisfaction will help to know the information on both the positive and negative aspects in daily working condition [4]. To get better satisfaction we have to evaluate and measure JS and also reward and recognition. The purpose of the study is to identify the level of the JS among physiotherapy professionals working in private sectors in Dhaka city.

\section{MATERIALS AND METHODS:}

A 103 physiotherapy professional completed a five years university degree (4 years academic +1 -year internship) were included with their written informed consent and information was collected from June to November 2018. A crosssectional study was conducted where physiotherapy professionals were working at the different private institute, hospital, clinics, and chamber situated at Mirpur, Mohakhali, Uttara, Mohammadpur, and Shamoli in Dhaka city. Data were collected from the physiotherapy professionals who had a minimum 1 year of professional experienced in the current job.

Investigators explained the purpose of this study before the data collection. Purposive sampling technique was used and questionnaires completed by face to face interview. The data were included about the information of sociodemographic factors, work-related factors, and questions about JS. Level of JS was evaluated by 4-point Likert scale graded and ranging as $1=$ Strongly dissatisfaction, $2=$ Dissatisfaction, $3=$ Satisfaction, $4=$ Strongly satisfaction [7].

The survey comprises 25 items in 3 categories. Each category contains sub-items. JS is measured by 10 survey questions to see satisfaction levels, such as workplace environment, salary structure, and promotion, security, comfortable with superior authority, colleague's behavior, and cooperation from the colleague, job satisfaction, and job stress.

Data were analyzed by SPSS (version-20). Chi-square test was used where the p-value indicated at the level of significance $(\mathrm{p}<0.05)$.

\section{RESULTS:}

Table 1 shows that the maximum $(\mathrm{n}=78,75.7 \%)$ participants belong to the age group 26-30 years, followed by 29.09 $( \pm 3.338)$ years in mean age. Male participants $(56.3 \%)$ were more than female (43.7\%). According to the educational background, $68.9 \%$ of participants were graduate and $31.1 \%$ participants were post-graduate. Among the participants $(\mathrm{n}=103)$, married $(56.3 \%)$ were more than unmarried (43.7\%). Salary range 20000-40000 BDT was most (46.6\%) of the participants, followed by 25381.55 ( \pm 11458.679$)$ BDT in average salaries.

Regarding work-related factors, the majority (63.1\%) of the participants' working duration was 7-10 hours and about two-third (79.6\%) of the participants had 1-5 years of job experience. Most (63.1\%) of the participants' transportation were by bus as shown in Table 2 .

Considering the satisfaction levels, about two-third $(76.7 \%)$ of the participants were satisfied with their working environment. $51.5 \%$ of the participants stated dissatisfaction on salary matter. More than half $(58.3 \%)$ of the participants were dissatisfied about the promotion system; maximum $(62.1 \%)$ was satisfied with their leave policy. About two-third $(74.8 \%)$ of the participants reported their satisfaction in the security of job place. Most of the participants $(76.7 \%)$ said satisfaction in reply comfortable of their senior. Maximum (78.6\%) reported satisfaction of their colleague's behavior. Above half (54.3\%) of the participants confirmed dissatisfaction with work-related stress. However, more than half $(58.3 \%)$ of the participants were satisfied with their job and about one fourth $(28.2 \%)$ replied dissatisfaction as shown in Table 3.

Table 4 shows that there was a highly significant relationship found between salary and job satisfaction $(0.001<0.05)$ and no-significant relation found between age $(0.294>0.05)$ and sex $(0.453>0.05)$.

\section{DISCUSSION}

The purpose of the study was to determine the job satisfaction level among Dhaka based physiotherapy professionals. The principal finding of this study was satisfactory on job satisfaction among Dhaka based physiotherapy professionals in the private sector. A study in Turkey by Eker et al. [6] stated that the percentage of job satisfaction among physiotherapy professionals was $45.5 \%$. Another study in Saudi Arabia by Aleisa et al. [8] identified that job satisfaction in physiotherapist has mostly shown high levels. Satisfaction level was explored by 4-point Likert scale grading and ranging with strongly dissatisfaction, dissatisfaction, satisfaction, strongly satisfaction. Investigators tried to find out the specific satisfaction level by answering some related questions from the participants. The current study found about two-thirds of the participants agreed with satisfaction about their working environment, but half of the participants dissatisfied with their salary structure and there was a highly significant relationship found between salary 
Table 1. Socio-demographic characteristics $(n=103)$.

\begin{tabular}{lcl}
\hline Variables & $(\mathrm{n})$ & $(\%)$ \\
Age group (In years) & & \\
26 to 30 & 78 & 75.7 \\
31 to 35 & 19 & 18.4 \\
36 to 40 & 6 & 5.8 \\
Mean $\pm \mathrm{SD}=29.09 \pm 3.338$ & \\
Sex & & \\
Male & 58 & 56.3 \\
Female & 45 & 43.7 \\
Education background & & \\
Graduate & 71 & 68.9 \\
Post Graduate & 32 & 31.1 \\
Marital status & & \\
Married & 58 & 56.3 \\
Unmarried & 45 & 43.7 \\
Salary (BDT) & & \\
<20000 & 43 & 41.7 \\
20000-40000 & 48 & 46.6 \\
40000-60000 & 12 & 11.7 \\
Mean \pm SD $=25381.55 \pm 11458.679$ \\
\hline
\end{tabular}

*BDT $=$ Bangladeshi Taka

Table 2. Work related factors

\begin{tabular}{lll}
\hline Variables & $(\mathrm{n})$ & $(\%)$ \\
Working Hour & & \\
$4-7$ & 32 & 31.1 \\
$7-10$ & 65 & 63.1 \\
$>10$ & 6 & 5.8 \\
Job Experience (In Years) & & \\
1-5 & 82 & 79.6 \\
$5-10$ & 14 & 13.6 \\
10-15 & 6 & 5.8 \\
Transportation & & \\
Private car & 4 & 3.9 \\
Bus & 65 & 63.1 \\
Rickshaw & 11 & 10.7 \\
Motorcycle & 15 & 14.6 \\
Others & 8 & 7.8 \\
\hline
\end{tabular}

Table 3. Satisfaction related factors (4 Point Likert Scale)

\begin{tabular}{|c|c|c|c|c|c|}
\hline $\begin{array}{l}\text { Sl. } \\
\text { No. }\end{array}$ & Satisfaction Level & $\begin{array}{l}\text { Strongly } \\
\text { Dissatisfaction } \\
\mathrm{n}(\%)\end{array}$ & $\begin{array}{l}\text { Dissatisfaction } \\
\mathrm{n}(\%)\end{array}$ & $\begin{array}{l}\text { Satisfaction } \\
\mathrm{n}(\%)\end{array}$ & $\begin{array}{l}\text { Strongly } \\
\text { Satisfaction } \\
\mathrm{n}(\%)\end{array}$ \\
\hline 1 & $\begin{array}{l}\text { Are you satisfied with the working } \\
\text { environment? }\end{array}$ & $0(0.0)$ & $17(16.5)$ & $79(76.7)$ & $7(3.9)$ \\
\hline 2 & $\begin{array}{l}\text { Are you satisfied with the salary } \\
\text { structure? }\end{array}$ & $11(10.7)$ & $53(51.5)$ & $35(34.0)$ & $4(3.9)$ \\
\hline 3 & $\begin{array}{l}\text { Are you satisfied with the promotion } \\
\text { system? }\end{array}$ & $5(4.9)$ & $60(58.3)$ & $30(29.1)$ & $8(7.8)$ \\
\hline 4 & Are you satisfied with the leave policy? & $0(0.0)$ & $35(34.0)$ & $64(62.1)$ & $4(3.9)$ \\
\hline 5 & $\begin{array}{l}\text { Are you satisfied with the security of } \\
\text { job place? }\end{array}$ & $0(0.0)$ & $8(7.8)$ & $77(74.8)$ & $18(17.5)$ \\
\hline 6 & $\begin{array}{l}\text { Are you feeling comfortable with your } \\
\text { senior? }\end{array}$ & $0(0.0)$ & $15(14.6)$ & $79(76.7)$ & $9(8.7)$ \\
\hline 7 & $\begin{array}{l}\text { Are you satisfied with your colleague's } \\
\text { behavior? }\end{array}$ & $0(0.0)$ & $6(5.8)$ & $81(78.6)$ & $16(15.5)$ \\
\hline 8 & $\begin{array}{l}\text { Are you satisfied about cooperation of } \\
\text { colleague? }\end{array}$ & $0(0.0)$ & $10(9.7)$ & $81(78.6)$ & $12(11.7)$ \\
\hline 9 & $\begin{array}{l}\text { Are you satisfied with the stress of } \\
\text { your current job? }\end{array}$ & $7(6.7)$ & $56(54.3)$ & $36(34.9)$ & $4(3.8)$ \\
\hline 10 & Are you satisfied with the current Job? & $8(7.8)$ & $29(28.2)$ & $60(58.3)$ & $6(5.8)$ \\
\hline
\end{tabular}




\section{Job Satisfaction among Physiotherapy Professionals Working In Private Sectors of Bangladesh: A Cross-Sectional Study

Table 4. Association of job satisfaction with age, sex, and salary.

\begin{tabular}{|c|c|c|c|c|c|c|}
\hline Variables & $\begin{array}{l}\text { Job Satisfaction } \\
\text { Strongly Dissatisfaction }\end{array}$ & Dissatisfaction & Satisfaction & Strongly Satisfaction & Total & $\mathrm{p}$ value \\
\hline Age Group & & & & & & \multirow{4}{*}{.294} \\
\hline $26-30$ & $5(6.4 \%)$ & $23(29.5 \%)$ & $47(60.3 \%)$ & $3(3.8 \%)$ & $78(100.0 \%)$ & \\
\hline $31-35$ & $3(15.8 \%)$ & $4(21.1 \%)$ & $9(47.4)$ & $3(15.8 \%)$ & $19(100.0 \%)$ & \\
\hline $36-40$ & $0(0.0 \%)$ & $2(33.3 \%)$ & $4(66.7 \%)$ & $0(0.0 \%)$ & $\begin{array}{l}6 \\
(100.0 \%)\end{array}$ & \\
\hline \multicolumn{7}{|c|}{ Sex } \\
\hline Male & $3(5.2 \%)$ & $19(32.8 \%)$ & $32(55.2 \%)$ & $4(6.9 \%)$ & $58(100.0 \%)$ & \multirow{2}{*}{.453} \\
\hline $\begin{array}{l}\text { Female } \\
\text { Salary (BDT) }\end{array}$ & $5(11.1 \%)$ & $10(22.2 \%)$ & $28(62.2 \%)$ & $2(4.4 \%)$ & $45(100.0 \%)$ & \\
\hline$<20000$ & $2(4.7 \%)$ & $28(65.1 \%)$ & $13(30.2 \%)$ & $0(0.0 \%)$ & $43(100.0 \%)$ & \multirow{3}{*}{$.001^{*}$} \\
\hline $20000-40000$ & $5(10.4 \%)$ & $10(20.8 \%)$ & $29(60.4 \%)$ & $4(8.3 \%)$ & $48(100.0 \%)$ & \\
\hline 40000-60000 & $1(8.3 \%)$ & $2(16.7 \%)$ & $7(58.3 \%)$ & $2(16.7 \%)$ & $12(100.0 \%)$ & \\
\hline
\end{tabular}

$\mathrm{p}$ value reached from chi-square. Mark $\left({ }^{*}\right)$ represents a highly significant association of Job satisfaction with salary (p value .001$)$.

and JS that informed physiotherapy professionals are not getting sufficient wages for their job in our country. Dhaka is the main city of Bangladesh. Many renowned private and public hospitals, clinic, diagnostic centre, and physiotherapy institute are situated here, but the salary structure is not appropriate compared to other professionals. In Bangladesh, Physiotherapy professionals are working as a fixed position at many private organizations. In India, a study found the same results of dissatisfaction about salary [9]. On the other hand, they have no promotion system. So, most of them had dissatisfied about the promotion related question. In this study, the majority of the participants agree with satisfaction about their leave policy and security matter, but a study in India found dissatisfaction about security matter [9] The study revealed that working comfortably with senior, colleague behavior, colleague cooperation was showed satisfaction that helps to improve their job satisfaction. Answered 10 questions according to the Likert scale, Investigators found a fair amount of participants had the satisfaction and one-fourth of the participants replied dissatisfaction. Investigators found junior participants had more satisfaction in contrast senior participants had less satisfaction. A study in Nigeria, Ojoawo et al. [10] stated that there was a significant association between the level of satisfaction and age, marital status. But this study found there was no significant association between the level of satisfaction and age. Male were more satisfied with their job than female. The previous study found job satisfaction was significantly associated with gender [11] but this study found there was no significant relationship found between sexes with job satisfaction. The maximum participant's income range was 20000-40000 BDT. More than half of the participants had 7-10 of a working hour and two third of the participant's job experience was 1-5 years. Regarding job stress, more than half of the participants confirmed having job stress. According to Ogiwara and Araki [4], job dissatisfaction initiated due to mental tension. Srivastava and Singh [12] showed that the current workplace environment could increase the risk of stress among health care professional. Helalah et al. [13] stated that a high rate of stress and dissatisfaction among health professionals, including physiotherapist.

\section{CONCLUSION}

A fair amount of participants are satisfied with their current job. There are some factors are responsible to favor of satisfaction such as working environment, security, comfortable with senior and authority, and leave policy. But a high number of participants reported their dissatisfaction about their salary and promotion system. However, a significant relationship found between JS and salary whereas no significant relationship found between JS with age and sex. Some area like salary structure and promotion which if changed could lead to increase the satisfaction level among physiotherapy professionals.

Acknowledgement: We, the authors would like to thank all the participants for their due consent. Authors also acknowledge the support provided by the physiotherapy department of SAIC College of Medical Science and Technology, Mirpur; State College of Health Sciences, Dhanmondi; Institute of Health Technology, Mohakhali, Dhaka, and Physiotherapy Unit of Dhaka University.

Conflict of Interest: There is no conflict of interest regarding this article.

Disclosure of Benefits: No funding was received for this work from any organization.

\section{REFERENCES}

1. Alva, R. and Lobo, M.E. (2016). Job and Career Satisfaction among Indian and Rehabilitation. Physiotherapist. International Journal of Therapy, 25 (2). Retrieved from:

https://doi.org/10.12968/ijtr.2016.23.2.75

2. Anju, K.J. (2011). A study on Job satisfaction of Employees in BPCLkochi refinery limited, Ambalamugal. Conference: National conference on Emerging Trends in Business. Retrieved from:

https://www.researchgate.net/publication/281857611

3. Paul, E.S. (1997). Job satisfaction: Application, Assessment, causes, and consequences. Sage publications.

Retrieved from: http://dx.doi.org/10.4135/9781452231549

4. Ogiwara, S. and Araki, H. (2006) Job satisfaction among Physiotherapists in Ishikawa Prefecture, Japan. J.Phys.Ther.Sci, 18: 127-132.Retrieved from:

https://www.jstage.jst.go.jp/article/jpts/18/2/18_2_127/_pdf

5. Senduran, M., Unver, B. Kocak, F.U. and Narin, S. (2012). Job satisfaction among Physiotherapists living in Aegean Region of Turkey. Fizyoterapi Rehabilitasyon, 23(2):100-106. Retrieved from: https:// dergipark.org.tr/download/article-file/138076 
6. Eker, L., Tuzun, E.H., Daskapan, A. and Surenkok, O. (2004) Predictors of Job Satisfaction among Physiotherapists in Turkey. Journal of Occupational Health, 46:500-505. Retrieved from:

http://joh.sanei.or.jp/pdf/E46/E46_6_13.pdf

7. Brown, S. (2010). Likert Scale Examples for surveys (2010). ANR Program Evaluation. Lowa State University. Sorrel@ia

8. Aleisa, E., Tse, C., Alkassabi, O., Buragadda, S. and Melam, G.R. (2015). Predictors of global job satisfaction among Saudi Physiotherapists. Ann Saudi Med. 35(1), 46-50. Retrieved from:

doi: 10.5144/0256-4947.2015.46.

9. Gupta, N. and Joshi, S. (2013). Predictors of Job Satisfaction among Physiotherapy Professionals. Indian Journal of Physiotherapy and Occupational therapy, 7 (3):146-151. Retrieved from:

http://www.i-scholar.in/index.php/ijpot/article/view/42665

10. Ojoawo, A.O. Igudia, G.O., Mbada, C., Ayodele, O.T. and Adoedoyin, R.A. (2013). Assessment of Life Satisfaction among Physiotherapists from Selected Hospitals In South-Western Nigeria. Nigerian Journal Of Medical Rehabilitation, 16, (2): Retrieved from: https://www.njmr.org.ng/index.php/njmr/article/view/83

11.Alkassabi, O., Alsobayl, H. and Aleisa E. (2015). JOB SATISFACTION AMONG PHYSIOTHERAPISTS: DOES THE LEDERSHIP STYLE MATTER? WCPT Congress, 101(1) eS26-eS426. Retrieved from:

https://www.physiotherapyjournal.com/article/S0031-9406(15)00214-X/ pdf

12. Srivastava P. and Singh M.M. (2017). Job Satisfaction among healthcare professional in public and private health care setup in India. PARIPEX-Indian Journal of Research, 6(1):6-8. Retrieved from:

https://www.researchgate.net/publication/322084239

13. Helalah, A.S.M.A., Jorissen, S.L., Niaz, K., and Qarni, A.M.A.A. (2014). JOB STRESS AND JOB SATISFACTION AMONG HEALTH CARE PROFESSIONALS. European Scientific Journal, 10(32): 156-173. Retrieved from:

https:pdfs.semanticscholar.org/5ae3/058257f3e7418e4d152d56493e070d 08a995.pdf 